\title{
Interactive Teaching Methods as Pedagogical Innovation
}

\author{
Abykanova Bakytgul', Sadirbekova Dinara ${ }^{2}$, Sardarova Zhannat ${ }^{3}$, Khairzhanova \\ Akhmaral Kh${ }^{4}$, Mustagaliyeva Gulnara $S^{5}$, Tabyldieva Oryngul Dyysenbaevna ${ }^{6}$, \\ Abdol Eleonora $D^{7}$ and Bainazarova Tursynay ${ }^{8}$ \\ ${ }^{1}$ Candidate of Pedagogical Sciences, Associate Professor Kh.Dosmukhamedov \\ Atyrau University E01Y6P0, 1 Student Avenue, Atyrau, Kazakhstan \\ ${ }_{2}^{2}$ phd Doctor, Senior Teacher, Kazakh National Women's Teacher Training \\ University, 050043, Republic Of Kazakhstan, Almaty \\ ${ }^{3}$ Doctor Pedagogical Sciences, Associate Professor Republican Institute for Advanced Studies of Senior and \\ Scientific- Pedagogical Workers of the Education System of the, Republic of Kazakhstan Almaty \\ ${ }^{4}$ Candidate of Philology, Head of the Departament, Translation Studies And Foreign Languages, \\ Kh.Dosmukhamedov Atyrau University E01Y6P0, 1 Student Avenue, Atyrau, Kazakhstan \\ ${ }^{5}$ Senior Teacher, Department of Translation Studies and Foreign Languages, Kh.Dosmukhamedov \\ Atyrau University E01Y6P0, 1 Student Avenue, Atyrau, Kazakhstan \\ ${ }^{6}$ Candidate of Historical Sciences, the Associate Professor, the Caspian State University of Technology \\ and Engineering of Sh. Esenov, 32 Microregion Aktau, 130000, Kazakhstan \\ ${ }^{7}$ Associated Professor, Head of the Department, Methods of Foreign Language Teaching Department, \\ Kh. Dosmukhamedov Atyrau University. E01 Y6P0, 1 Student Avenue, Atyrau, Kazakhstan \\ ${ }^{8}$ Candidate of Pedagogical Sciences, Associate Professor Almaty, Kazakh National Women's Teacher \\ Training University, 050043, Republic Of Kazakhstan, Almaty
}

\section{ABSTRACT}

The transformations taking place at the global level bring changes to all spheres of human activity, including the educational system. Traditional learning forms that put the focus on the teacher while students are the passive participants of the educational process nowadays gave way to more effective interactive learning methods that fully engage students into the educational process. The article analyzes the changes taking place in the sphere of education today. After all, the orientation toward new goals of education requires a change in the methods and forms of the organization of the educational process. The author of the article cites a number of reasons, because of which interactive training becomes more widespread and relevant in the field of education. Next, different definitions of the concept of interactive learning are considered from the point of view of different authors. The similarities and differences in the understanding of this concept are described in more detail by different authors, the stages of interactive learning, its features are described. The article deals with the concept of interactive learning from different sides, in order to reveal its essence. The article emphasises the relevance of the use of interactive forms of education, analysing the concept of interactive learning.

KEY WORDS: INTERACTIVE LEARNING, BRAINSTORMING, ICT, ROUND TABLE, SIMULATION GAMES, ROLE-PLAYING GAMES, PROJECT METHOD, ACTIVE LEARNING, CASE STUDY, PROBLEM LECTURE, DIDACTIC GAMES, EDUCATIONAL PROCESS.

Biosc Biotech Res Comm P-ISSN: 0974-6455 E-ISSN: 2321-4007

\section{crossef}

Identifiers and Pagination

Year: 2021 Vol: 14 No (5) Special Issue

Pages: 171-175

This is an open access article under Creative

Commons License Attribn 4.0 Intl (CC-BY). DOI: $h t t p: / / d x$.doi.org/10.21786/bbrc/14.5/31

\section{INTRODUCTION}

The thoughts of the overwhelming majority of scientists and teachers have long been focused on the fact that the future of our civilization is closely connected with ensuring the development of the intellectual and creative potential of citizens and especially young people of school
Article Information

Received: $25^{\text {th }}$ Jan 2021 Accepted after revision: $28^{\text {th }}$ Mar 2021

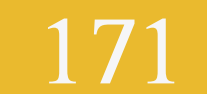


age. The acceleration of scientific and technological progress and the information revolution in modern society requires new approaches to training and education of the young generation. Traditional pedagogical approaches to the organization of the educational process more and more often do not satisfy the needs of both teachers and schoolchildren for effective and intensive knowledge of the world especially in relation to physics. Such knowledge forms a holistic scientific picture of the world, develops the personality of a graduate of a comprehensive school, who must continue his/her studies in a higher educational institution or realize himself in the chosen field of professional activity.

In these circumstances, the formation of motivation for teaching physics to students is one of the global problems of the modern school. Its relevance is due to updating the content of training, the significant development and implementation of active teaching methods through innovative technologies and especially information and communication technologies (ICT). A significant strengthening of the role of each student's independent (individual) work in the process of his/her education is generally aimed at the implementation of the subjectsubject approach in the organization of the educational process, on whose conscious understanding the learning achievements depend to a large extent. Therefore, the school is designed to teach each student the independent development and assimilation of the necessary information. New innovative teaching technologies are a combination of new systems and data processing methods, which are holistic training systems.

In modern conditions of numerous reforms, modernizations and updates, much attention is paid to the content of education and the technological basis of education, which has not been reformatted for centuries, is practically ignored. As a result, the quality of education is constantly deteriorating, as evidenced by the data of international studies PISA, TIMSS, PIRLS, TALIS, etc. In this regard, the issues of restructuring traditional pedagogical technology of the group method of teaching (GTM) and mastering the new and latest pedagogical technology of the collective method of teaching (CMT) are of particular relevance.

With the introduction of a competent approach to training, the urgent task of higher education is to develop students' applied skills. The question of activating students' independence and proactiveness is one of the most important problems of modern methodology of teaching special disciplines, pedagogy and psychology. Productive work of students in the higher educational institution should form not only solid knowledge, but also the ability to use them in various situations, independently acquire knowledge, shape experience in solving problem situations. The development of independence and proactive attitude does not happen by itself, it is the result of purposeful interaction and organization of the pedagogical environment, i.e. the use of pedagogical technology. The key ones are related to the use of active or interactive learning methods.
Aims of the Study: The aim of this article is to study the learning methods that turn the classes in the higher educational institutions into more effective and productive for students. The methodological framework includes the following methods: theoretical, analysis of pedagogical and psychological literature on the studied problem; analysis, synthesis, generalization, classification of information; empirical methods.

\section{RESULTS AND DISCUSSION}

The activation of the educational process is interpreted as the construction of such learning process, which involves the organization of the educational process on a scientific basis, creating conditions for creative thinking, research work of students, generates students' interest in their future specialty, etc.

In this regard, among the requirements for university teachers are the ability to work under new conditions, effectively use interactive methods, the ability to correctly convey their thoughts, prove their point of view and capacity for dialectic argumentation.

The success of the educational process for students is ensured by the implementation of:

- interactive methods;

- relationships between teachers and students based on partnership and cooperation.

Given these features, an important issue today is the training of future teachers in accordance with the requirements of modernity. The paradigm of education at the world level requires the focus of education on the result, on the student's personality, the construction of learning methods based on interpersonal relationships. The fact that Kazakhstan has chosen a democratic path of development increases the role of society in decisionmaking. In this area, methods that increase student activity are called interactive. These methods, which seem simple at first glance, have their own peculiarities and difficulties. This contributes to the situation when all students are involved in the cognitive process, having the opportunity to evaluate their knowledge and express their attitude to the studied objects. As emphasised Krusche with co-authors (2017) "interactive learning tightens the relationship between content delivery and problem solving in class by integrating multiple, small units of content delivery and content deepening through exercises."

In the course of dialogue-based training, students learn to think critically, solve complex problems based on the analysis of circumstances and relevant information, weigh alternative opinions, make thoughtful decisions, participate in discussions, and communicate with other people. To do this, the classes are organized in pairs and groups, research projects, role-playing games are used, documents and various sources of information are processed, and creative works are used. The student becomes a full participant in the educational process, 
student's experience serves as the main source of educational knowledge.

These behaviours are not learned by memorizing and rapidly and automatically reassembling them into a whole. Instead they must be constructed by learner's own attempts to use personal experiences and past learning to bring meaning to and make sense out of the content provided. According to Gleason and colleagues, it is important for teachers to make a transition of their concept of learning from simple knowledge acquisition, with learners memorizing by rote, toward more consequential knowledge construction with application of skills. Extending learning to include knowledge and skill applications can require a substantial change in how teachers both understand and approach the teaching-learning process. This transition moves from an instructor-centred and often lecture-based teaching format toward a learner-centred teaching format that may include discussion and case-based applications.

The functions of a teacher in higher education are not limited to the mere transfer of scientific knowledge (using passive teaching methods), they also include the choice of an optimal teaching strategy, the use of modern educational technologies aimed at creating a creative atmosphere of the educational process. Interactive learning process often involves the use of educational information technology (EIT) tools to facilitate the students' engagement and upgrade the overall process. EIT should be understood as an application of information technology to create new opportunities for transferring knowledge (teacher's activity), perceiving knowledge (student activities), assessing the quality of education and, of course, the comprehensive development of student personality during the educational process. Moreover, the main goal of educational informatisation is to train students for full and effective participation in the everyday social and professional fields of life in the information society.

Interactive learning technologies imply such an organization of the learning process in which it is impossible for a student not to participate in a collective, complementary process of learning based on the interaction of all its participants. Students use personal and social capability to work collaboratively with others in learning activities, to appreciate their own strengths and abilities and those of their peers and develop a range of interpersonal skills such as communication, negotiation, team work, leadership and an appreciation of diverse perspectives.

The main requirements for successful learning with interactive technology are as follows:

- Positive interdependence: group members should understand that shared learning activities benefit everyone;

- Direct interaction: group members should be in close contact with each other.

- Individual responsibility: each student must master the proposed material, and each is responsible for helping others. More capable students should not do other people's work.

- Developing teamwork skills: students must master the interpersonal skills necessary for successful work, such as interviewing, assigning, and scheduling tasks.

- Performance evaluation: during group meetings, it is necessary to allocate special time so that the group can evaluate how well it is working.

The difference between interactive learning methods and traditional learning methods is the use of life experience, the disclosure of personal and professional abilities through the analysis and systematization of information. In the traditional system, instruction was teacher-centred and the students' needs and interests were not considered. This is when students' instruction must change into a method in which their needs are considered and as a result of the mentioned method active behaviour change occurs in them. Modern higher education training involves not only students' acquisition of knowledge and the formation of professional skills, but also the development of creative and communicative abilities of the individual in the process of active cognitive activity. The practical application of problem-based and developmental learning has led to the emergence of socalled active methods that combine means and forms of learning that stimulate cognitive activity and create conditions for creativity and collaboration between teachers and students.

If the classical teaching method allows evaluating theoretical knowledge more accurately, the interactive one requires evaluating the correct construction of the speech, reasoning, possession of the categorical apparatus, the desire to identify the content of concepts, the ability of students to think logically, make decisions, and offer alternatives that were previously ignored. An important factor is taking an active part in the discussion and preparing the final report on the issue under discussion. Through interactive methods, students master the following knowledge, qualifications, skills and abilities:

- development of critical thinking and reflective reasoning abilities;

- analysis and evaluation of own ideas and actions;

- independent understanding, comprehensive analysis and ability to select/filter information;

- independent formation of new knowledge;

- participation in discussions, defending own opinion;

- making decisions and solving complex issues.

Therefore, in the process of interactive learning, students should be prepared for the following actions:

- collaboration;

- activity in terms of perception, communication and sociality.

In the process of interactive learning, students learn to formulate their opinions, correctly convey their thoughts, 
justify their opinions, conduct a discussion, listen to others, respect and consider other opinions and points of view.

Interactive training includes the following types of work:

1. Brainstorming: a flow of questions and answers, or suggestions and ideas on a given topic, in which the analysis of the correctness is made after the activity.

2. Interactive lesson with the use of audio and video materials, ICT. For example, online tests, working with electronic textbooks, training software, and training websites.

3. Round table (discussion, debate): a group type of activity that involves a collective discussion of problems, suggestions, ideas, opinions by students and a joint search for solutions.

4. Business games (including role-playing, simulation games, etc.) are a widespread method that can be used even in elementary school. Business roleplaying game is a specific type of human interaction that is aimed at simulation of a set reality providing its participants with the necessary freedom of actions within this reality. During the game, students play the role of participants in a particular situation, trying on different professions.

5. Aquarium is one of the types of business game that resembles a reality show. In this case, the given situation is played by 2-3 participants. Other students stay watching and analyse not only the actions of the participants, but also the options and ideas proposed by them.

6. Project method implies the independent development of a project by students on the topic and its subsequent defence.

7. Presentations are the easiest and most accessible method to use in the classroom. The method implies a demonstration of slides prepared by the students on a particular topic.

8. Case study have been used as learning method since the last century. It is based on the analysis of simulated or real situations and the search for a solution. There are two approaches to creating cases: American school offers a search for a single correct solution to the problem; European school, on the contrary, welcomes the diversity of solutions and their justification.

9. Problem lecture, in contrast to the traditional one, implies knowledge transfer that takes place in an active form. That is, the teacher does not present previously prepared statements, but only puts questions and indicates a problem. The rules are drawn by the students themselves. This method is quite complex and requires students to have a certain experience of logical reasoning.

10. Didactic games, unlike business games, are strictly regulated and do not involve the development of a logical reasoning to solve the problem. Game methods can also be referred to as interactive learning methods. It depends on the choice of game. Thus, popular games-adventures, performances, quizzes, humour games are techniques from the array of interactive methods, as they involve interaction of students with each other. The didactic games integrated into the lessons bring variety, joy, prevent monotony and boredom, the integration of the game as an active-participative method in the teaching-learning-evaluation process determines a greater efficiency of the lessons, reflected in the results of the students. to the development of the inventive and creative spirit, of the thought and imagination, of the interest for lessons. The basket method is based on simulating the situation. For example, a student should act as a guide and conduct a tour of a historical museum. At the same time, student's task is to collect and convey information about each exhibit.

Conducting an interactive lesson requires following a particular algorithm:

- Preliminary methodological preparation. The teacher selects a topic, situation, identifies concepts, terms, documents to be learned, and selects the appropriate form of conducting an interactive lesson that is most effective for certain group on a given problem.

- Conducting a lesson. Such a lesson includes an introduction, the main part and summing up. The teacher informs the topic and purpose of the lesson, students get acquainted with the problem situation, the goal of which is to achieve its solution, under the conditions and rules of working in groups. Since conducting such an activity should take place after the basic concepts and definitions of a given topic were learnt, based on the knowledge base available to students, the teacher should seek to the assimilation of the conceptual framework, establish the connection between the new material and that was previously learned. The lesson should be lively and interesting, but at a high methodological level. Dialogue and cooperation are the main key concepts at this stage. The lesson is conducted according to a pre-developed scenario. The specific content of an interactive lesson is determined by its type and form.

- Summing up the lesson. This stage begins with self-evaluation of students' activities, reviewing the responses of other students, and emotional evaluation of the lesson. Then the evaluation part is carried out (the attitude of participants to the content aspect of the methods used, the relevance of the chosen topic, etc.). This reflection ends with general conclusions made by the teacher.

- Thus, interactive learning methods based on interpersonal relationships meet the paradigm of modern education aimed at "personal development". At the same time, interactive methods not only form the activity of perception and personal significance in learning, but also develop them. 


\section{CONCLUSION}

Nowadays, higher education training should provide not only for students' passive acquisition of knowledge and the formation of professional skills, but also for the development of creative and communicative abilities of the individual in the process of active cognitive activity. The practical application of interactive learning involves active methods that combine means and forms of learning that stimulate cognitive activity and create conditions for creativity and collaboration between teachers and students. The conducted analysis showed that interactive learning methods greatly contribute to the development of student's independent thinking activity and lay the ground for the student-teacher or student-student collaboration, and thus bringing educational process closer to the every-day communicative reality of the future specialists when they will be required to seek solutions through teamwork. During such interactive classes, students share their knowledge and opinion, jointly developing the right solutions. The interactive learning forms increase students' motivation and thus enhances the productivity of the educational process. Therefore, successfully combining the traditional and interactive learning methods increases the involvement of students into thelearning process and contributes to the development of students' independence.

\section{REFERENCES}

Abykanova, B., Bilyalova, Zh., Tashkeyeva, G., Aldibekova, Sh., Nugumanova, S., Dautkulova, A., Shakibayeva, A., \&t Kubekova, S. (2020a). Professional competencies and methods for their formation in the university. Ad Alta Journal of Interdisciplinary Research, 10(1), 59-62

Abykanova, B., Kussainov, G. M., Mukhametkaly, M. M., Saparova, G., Utenova, B., Shuakbayeva, R. S., Nugumanova, S., \&t Kariyev, A. D. (2020b). Formation of communicative competence of students in the information educational environment of an urban school. Ad Alta Journal of Interdisciplinary Research,
10(1), 89-92

Abykanova, B., Yelezhanova, Sh., Koishigulova, L., Myrzasheva, A., Shazhdekeyeva, N., Saltanova, G., Akhmurzina, T., \& Turmukhanova, G. (2020c). The use of modern information technologies in the educational process. Ad Alta Journal of Interdisciplinary Research, 10(1), 37-40.

Bidabadi, N. S., Isfahani, A. N., Rouhollahi, A., EtKhalili, R. (2016). Effective teaching methods in higher education: requirements and barriers. Journal of Advances in Medical Education \&t Professionalism, 4(4), 170-178.

Dvulichanskaya, N. N. (2011). Interactive learning methods as a means to form the key competencies. NaukaiObrazovanie, 4. http://technomag.edu.ru/ doc/172651

Gagach, M. G. (2012). Active learning methods in the system of in-university training of specialists for work with youth. Vestnik MGUKI, 4(48), 149-152.

Krusche, S., Seitz, A., Börstler, J., Bruegge, B. (2017). Interactive learning - increasing student participation through shorter exercise cycles. Geelong, VIC, Australia.

Kussainov, G. M., Abdol E. D., Mukhambetov, Z. M., Mukhametkaly, M.M., Sadirbekova, D., Shakhtybayeva, Z,T., Seidakhmetov, M.,; Nishanbayeva, S. Information technologies as a determining factor of development of objects of social-infrastructural centers of the region. Ad Alta Journal of Interdisciplinary Research, 10(1), 97-99

Nae, F. L. (2019). Teaching-interactive method used in the teaching-learning process. Pro Edu. International Journal of Educational Sciences, 1, 27-33.https://doi. org/10.26520/peijes.2019.1.1.27-33

Pafifova, B. K. (2015). Situation-based role-playing games as one of the forms of interactive learning methods in the higher school. Vestnik Maykopskogo Gosudarstvennogo Tekhnologicheskogo Universiteta, 1, 110-116.

Sentham, S. (2018). Interactive teaching strategies. Journal of Applied 